\title{
Barriers to women in the UK construction industry
}

\author{
Lisa Worrall \\ Centre for Construction Innovation, School of the Built Environment, \\ University of Salford, Manchester, UK \\ Katy Harris and Roy Stewart \\ School of the Built Environment, University of Salford, Manchester, UK \\ Andrew Thomas \\ Centre for Construction Innovation, School of the Built Environment, \\ University of Salford, Manchester, UK, and \\ Peter McDermott \\ School of the Built Environment, University of Salford, Manchester, UK
}

\begin{abstract}
Purpose - This paper aims to identify the main barriers that lead to the under-representation of women in the UK construction industry. The study, funded by ConstructionSkills, seeks to explore the issues that women face and investigate the potential positive impact that continuous professional development (CPD) may have upon improving the retention and career progression of women.

Design/methodology/approach - The study uses an open-ended grounded theory (GT) approach, including 231 semi-structured questionnaires and nine focus groups with women from a range of professional occupations. All the findings were analysed using keyword analysis to identify the top two barriers that women face, alongside a series of cross-cutting key themes and issues.

Findings - The findings reveal that male-dominated organisational cultures and inflexible working practices are the main barriers to women in the UK construction industry, irrespective of job role or profession. This paper concludes by arguing for a sea-change in the expansion of CPD opportunities for women in managerial, confidence and communication based skills, with accompanying networking and support systems to facilitate the retention and advancement of women in the industry sector.

Research limitations/implications - Due to the research approach, the data are not generalisable. Therefore, researchers are advised to research and test the findings with a larger group. Researchers are also recommended to investigate the impact of expanded CPD opportunities for both men and women.

Originality/value - The paper puts forward a business case for the advancement of specific CPD training for women, to facilitate the expansion of equality and diversity in the workforce in the UK construction industry.
\end{abstract}

Keywords Construction industry, Human resource management, Organizational culture, Gender Paper type Research paper

\section{Introduction}

The most up to date calculations of price, cost indices and outputs reveal that the UK construction industry contributes a healthy 6\% of the country's Gross Domestic Product (GDP), Office for National Statistics (ONS, 2008). However, despite the negative impact of the credit crunch, the industry sector still faces an ongoing skills shortage and diversity based recruitment levels are currently inadequate in meeting this severe skills gap (ConstructionSkills, 2008). The UK construction industry is attempting to fill this gap in the short term by hiring workers from low wage economies, rather than recognising the longer term business case advantage of expanding the recruitment of women (Gurjao, 2006). Although there has been a numerical increase in the numbers of women and Black and Minority Ethnics (BMEs) entering the industry, this is only in line with the overall growth of the industry sector. In real terms, diversity based percentiles have remained relatively unchanged, consisting of between 10-12\% of women and 2-4\% of BMEs, since the year 1990. The low numbers of women in the UK 
construction industry lie in stark contrast with the current all-industry employment standard of $46 \%$ for women and $8 \%$ for BMEs (ConstructionSkills, 2008). These issues also extend beyond the UK to European markets in terms of concerns over Human Resource (HR) management (Schloesser et al, 1999).

The latest governmental figures from the Office for National Statistics (2008) have been a reweighted since May 2008. Figures can therefore vary within a few percentile according to differing measurements (Gale and Davidson, 2006). For this paper, those put forward by the latest governmental population weightings and employee base from the Office for National Statistics (ONS, 2008) will be utilised and are listed in Table 1. In addition to a lack of gendered diversity there is the issue of a 'workforce time bomb' of a rapidly ageing workforce (ConstructionSkills, 2008). There is a year-on-year increase in workers who are heading towards retirement age with a current inadequate supply of replacement workers (Gurjao, 2006). For example, those workers aged over 40 have increased on average by $2 \%$ each year since 1990 with those aged over 60 doubling from 4\% of the workforce in 1990 to $8 \%$ in 2007, ConstructionSkills (2008).

\begin{tabular}{clllllll} 
& & \multicolumn{3}{c}{ Employees (thousands) } & \multicolumn{3}{c}{ Self-Employed (thousands) } \\
Year & Quarter & Men & Women & Total & Men & Women & Total \\
2007 & Q1 & 1,250 & 189 & 1,438 & 888 & 22 & 910 \\
2007 & Q2 & 1,257 & 196 & 1,452 & 886 & 20 & 906 \\
2007 & Q3 & 1,327 & 191 & 1,519 & 862 & 18 & 880 \\
2007 & Q4 & 1,310 & 191 & 1,501 & 860 & 16 & 876 \\
2008 & Q1 & 1,280 & 199 & 1,480 & 874 & 19 & 894 \\
& \multicolumn{3}{c}{ Source: ONS (2008) based on Labour Force Survey (2004) }
\end{tabular}

Table 1: UK Construction industry employees by gender

Chan and Dainty (2007) argue in favour of a conceptual move towards a knowledge economy based upon principles of lifelong learning to improve the skills shortage. However, they point out that the organisational culture and make-up of the industry sector is hampering attempts at progress due to "... the small firms who make up the vast majority of employers within the sector, normative labour market and taxation policies and quasi-regulatory attempts to control the industry's employment and training practices have seemingly done little to safeguard the longterm sustainability of skills provision." (Chan and Dainty, 2007, p. 375). The argument outlined above is of great interest to the authors of this paper, as it highlights some of the potential challenges inherent in the unique organisational culture and formation of the UK industry sector in providing effective skills training and in meeting the skills gap. Furthermore, these problems are predicted to continue (Chartered Institute of Building, CIOB, 2008) and highlight potential obstacles in the provision of training to promote and expand the numbers of women in the industry sector where they are severely under-represented (Agapiou et al, 1995).

This paper sets out to investigate the barriers that women face in working in the UK construction industry. As this is a complex area of research, the authors will attempt to identify if there are one or two main barriers, while maintaining an awareness of potential complex crossfertilisations with other issues and themes. This paper will also investigate if there are indicators of age or job role differences in the barriers faced by women. The specific cohort of women 
have been drawn from the Women and Work: Sector Pathways Initiative funded by ConstructionSkills. The origin of funding for this project is to increase the numbers of women in industry sectors where they are under-represented with the provision of training and support opportunities. Thes 'training cohort' consists of varying age groups and professions that originate from professional, managerial, administrative and other skills backgrounds. The Continuous Professional Development (CPD) on offer is focussed upon communication, teamwork and management based training knowledge and skills which can be generically referred to as 'soft skills' training. This type of training was specifically chosen due to its high demand by women placed at the very start of the Women and Work project. This demand formed the basis of the origins of this research paper which has in turn led to a literature review which identified and strengthened the inductive research focus into organisational cultures. This paper will investigate the barriers that women face and analyse the potential role and impact of 'soft skills' training in helping to address identified barriers.

This paper will begin by providing a background literature review of organisational cultures existent within the UK construction industry, and not of societal cultures which can also be engendered (Hofstede and Hofstede, 2004). The authors recognise that the limited data prevents an overall generic analysis of this type. Next, the paper will draw upon some of the prior research carried out in the specific area of the UK construction industry. It will not generalise to research being undertaken in the Science, Engineering and Technology (SET) field. The reasoning behind this stance is to specifically focus upon an analysis of the unique formation and organisational cultures existent in the UK construction industry sector which possess an inherently large number of fragmented Small and Medium Enterprises (SMEs) and organisations. Within the limited space available in this paper, the authors aim to offer the reader the most thorough debate as possible on the construction sector itself, rather than include it within a broader brush of 'gender themed' research. Indeed, we have read with great frustration that some view it as acceptable to amass together other industries under one gendered framework of analysis. Instead, in the space available, we will attempt to analyse, assess and discuss our recognition of the complex and unique character existent within the UK construction industry sector.

The next section of our paper outlines a specification of the methods and tools that were utilised within the project. Here, the usage of the Grounded Theory (GT) is discussed, whereby issues and literatures have become emergent via an ongoing analysis of the empirical data. In this methodology, it is the empirical data that is central in directing the discovery and expansion of the background literature, in an ongoing and emergent process. The methodology section will outline the number of participants, their professions and age groupings and the nature and origin of the data will be given. This paper concludes by identifying key themes, issues and areas and argue for a need to enact positive change with the inclusion of CPD provision for women in an ongoing basis. This paper concludes by arguing for further research and analysis to more fully explore the role and impact of these changes in the facilitation of workforce equality and diversity over the longer term.

\section{Organisational World: A History of Fragmentation}

To more fully understand the UK construction industry as it stands today, there is a need to briefly view it within its historical context. In the 1980s the industry was changed with the 
opening up of a freer market and weakening levels of direct governmental involvement. This led to a greater fragmentation of the industry, with contractors increasingly sub-contracting work. This, in turn, facilitated a working environment that was more competitively and aggressively led by price and risk factors. By the 1990s, the industry sector hit a recession, with the collapse of over-inflated prices in the housing market. These problems were exacerbated with attempts by the UK government to control inflation and encourage external investments with overly high exchange rates, unnaturally low interest rates and this in turn fed into economically damaging cycles of boom and bust.

Within this economic climate, the UK government commissioned a report by Sir Michael Latham (1994) entitled 'Constructing the Team' in an attempt to identify the problems existent within the struggling construction industry sector. The report recommended the importance of having wider economic stability and for greater governmental direct contact, in order to improve both the economic and work flow base of the sector. The report included over 30 recommendations on how to achieve this, far too many to mention within the limited space of this paper. Interestingly, Latham (1994) also identified a number of inherent problems within the industry itself; including its natural fragmentation due to; prior privatization policies and the reduction of governmental involvement, a severe skills shortage, a lack of training of its workforce and its overall poor image. The report concluded by calling for greater uniformity of the sector, for the promotion and utilisation of best practice guidelines and for a change in UK legislation to encourage the resolution of 'adversarial' disputes that had now become commonplace in the industry sector.

Due to a disappointing lack of progress in the years that followed, a further report was commissioned by the government and completed by Sir John Egan (1998). In this report, Egan noted that research and development had fallen by nearly $80 \%$ since 1981; that workforce trainees had almost halved since the 1970s and that the industry was both time and price inefficient with low levels of client satisfaction. These findings led to 'Rethinking Construction' initiatives that eventually formed Constructing Excellence, which still exists today. Egan (1998) also called for the standardisation of quality assessments and policies and for the introduction of partnering strategies to assist in reducing the effect and impact of industry fragmentation. The report also recommended the need for improved Health and Safety training for staff and for training at all levels; with a view that quality and training that would derive beneficial outcomes. Of the many reports that have been commissioned by the UK government over the years, a main area of ongoing concern is the fragmentation of the industry sector. This area of the UK construction industry poses two problems; 1) there are too many companies involved in the construction process, with subsequent wastage along the supply chain where information on potential improvements can get lost. This is due to the sheer volume of companies involved in these processes and; 2) the vast majority of companies are small with only a small number of employees (Dainty et al, 2005). This leads to limited abilities and resources being available to impact upon the supply chain.

In addition to its fragmented and competitive nature, the construction industry often places the value of 'profit over people' (Dainty et al, 2007). This organisational culture undervalues both the industry itself and the women who work in it (Bagilhole et al, 1997). Chan and Dainty (2007) argue that the issue of skills and people covers two areas; 1) of shortages in quantity and 2) 
shortages in area, i.e. gaps. These two areas of concern need to be differentiated but also seen in the context of the industry sector as a whole, in order to give a broader picture of the problems inherent in the industry.

Efforts to explore the issues surrounding the entry, retention and progression of BMEs (Commission for Architecture and the Built Environment (CABE) 2005, CIOB, 2008) and of women (Ellison, 2003, Greed, 2000, Dainty et al, 2000, Gale and Davidson, 2006, Worrall et al, 2008 ) in the built environment profession is ongoing. Of the 'untapped resource' of women (Fielden et al, 2000) that overcome the initial barriers of entry; such as the industry's poor image and prejudicial training and recruitment barriers, women also face barriers such as existing sexist attitudes and stereotypes that can place limitations on their roles and abilities, while at the same time having to cope with difficulties in their work-life balance. Indeed, for nearly ten years, research has outlined that family friendly policies aid the retention of white collar workers in this sector (Lingard 2000). In this currently restrictive working culture, theorists such as Ellison (2003) are still arguing for the need to introduce improved flexible working practices and opportunities and for promotion and training and this call is still continuing (Worrall et al, 2008). The need to promote expanded levels of equality and diversity in the construction industry sector are ever-more prevalent. This is increasingly the case due to the latest UK governmental policy directives outlined in the Equality Bill (Equalities Office, 2008). This new legislation stipulates that companies will need to introduce greater levels of organisational transparency and of workforce auditing and monitoring, in order to enhance their ability to procure contract work. There has long been the view that changes in the industry's old fashioned, inflexible and longhours working environment will lead to improvements in the adversarial organisational culture inherent in the industry (Gale 1992). Such changes, whether spontaneous or led by governmental legislation, could lead to an increased ability to meet future workforce demands (Agapiou et al, 1995).

Although these claims need to be tempered within the current economic climate, the CIOB (2008) predict that senior and middle managerial skills will be in the greatest demand as far ahead as 2011; second only to demand for Crafts and Trades skills. This demand is being boosted with governmental plans to build more schools in the UK, ambitious housing targets and with the 2010 London Olympics. Therefore, the application of managerial and 'soft skills' training to our trainee cohort and an analysis of their efficacy is very timely for two reasons; 1 ) it provides a skills set that is predicted to be in the highest demand as far ahead as the year 2011, second only to Craft and Trades skills; and 2) the managerial and 'soft skills' gained serve to help women to negotiate and traverse difficult working environments and organisational cultures. This paper will now discuss the methodology utilised for the gathering of empirical data and provide details of the subject cohort.

\section{Methodology}

The research project has utilised Glaser's (1992) GT methodology which is based largely upon qualitative data. However, our methodology also includes a quantitative analysis of the main barriers that women face within differing age groups and professions. We view GT as being ideal for this type of study as it is inherently inductive in nature. With GT, theories, issues, themes and sub-themes become emergent within an iterative process of an analysis of the data. For example, even at the start of our study, data emerged from many women communicating 
direct to the research team a strong need to receive CPD in 'soft skills' training, to assist them in working within difficult white male dominated organisational cultures. This in turn inductively led to our analysis of literature on UK organisational cultures in the UK construction industry. From these initial findings and insights, we then designed our semi-structured questionnaires and focus groups topics to further investigate and explore these issues. It should be stated that we deliberately designed our questionnaires and focus groups to be semi-structured; to allow for additional issues and findings to become emergent during our research process. An important feature of GT is theoretical sensitivity. This is where researchers develop insights from initial data that can lead to a research situation. These insights are conceptual rather than concrete and this initial stage is referred to as the creative aspect of GT. From these first steps, researchers can then obtain experience and knowledge in order to recognise important data to formulate and conceptualise dense theory.

The participant cohort consisted of a diverse and random grouping of women aged between 1865 years within administrative, professional/managerial and other roles (e.g. customer liaison managers). It should be stated that the project group does not include those from the Craft and Trades. This group was excluded from this study due to their training and support being undertaken directly by the Standards and Qualifications team within the UK's Sector Skills council for construction, ConstructionSkills.

The numbers of individuals within each of the nine focus groups varied between 20-30 people for each training session. At each training event, participants sat at a circular shaped table sized to accommodate between 6-8 people. These seating arrangements were deliberately designed to facilitate face-to-face interactions with other subjects as part of a networking and action based learning setting and process. Prior to each focus group taking place, participants were given a full background surrounding the research aims of the project and were informed of the confidentiality and anonymity of the research data. All participants were informed of the voluntary nature of investigation and 231 semi-structured questionnaires were returned.

All respondents in both the focus groups and the semi structured questionnaires were asked to identify their age grouping and their profession categorisation. Respondents were also asked to provide information on how long they had worked in the construction industry, to outline the top two barriers that they had faced in staying or progressing and any other additional personal or professional barriers that they had faced (or are facing) in being a woman in the industry sector. Additional questions were also asked regarding what type of training they would find useful in the future and whether they had any suggestions for training or support that would help women enter, say or progress within the UK construction industry. The questionnaires were handed in either at the end of each workshop or posted back to the research team after the training event had taken place. All research findings were analysed in an ongoing process and themes were identified via usage of keyword analysis in a series of Word documents. Both the literature and empirical data has been analysed in an ongoing GT basis, to which the findings have become emergent regarding the issues and identified themes, which will be both illustrated and discussed later in this paper.

The quantitative data findings from the questionnaires in Table 2 outline the age and broad profession category of the women trainee delegates. The table indicates a very complex picture 
of the potential for the growth of women in the UK construction industry based upon the range of their age groupings and profession. Table 2 seems to indicate that the majority of women are either in the 25-35 year or 36-45 year age group; with a smaller number being present in the 1824 or 56-65 year age group. With regards to job roles, 78 were professionals/managers, 140 administrative and 13 in other job role categories, such as customer liaison officers

\begin{tabular}{lcccccc} 
& \multicolumn{7}{c}{ Age (years) } \\
Profession & $\mathbf{1 8 - 2 4}$ & $\mathbf{2 5 - 3 5}$ & $\mathbf{3 6 - 4 5}$ & $\mathbf{4 6 - 5 5}$ & $\mathbf{5 6 - 6 5}$ & $\mathbf{6 5 +}$ \\
Professional/Managerial & 4 & 20 & 41 & 6 & 7 & 0 \\
Administrative & 2 & 45 & 52 & 27 & 14 & 0 \\
Other & 3 & 3 & 1 & 2 & 4 & 0 \\
Total & 9 & 68 & 94 & 35 & 25 & 0 \\
& & Sub Total & & & & $\mathbf{2 3 1}$
\end{tabular}

NB: Trainee cohorts do not include those from Craft \& Trade professions

Table 2: Profession and Age

It should be stated that the numbers of women in our study were too small to be statistically significant and that the cohort may also have been affected by the nature and type of the 'soft skills' training on offer. However, it was of interest to note the apparent 'bell shape' distributions of age ranges that seem to have occurred in our trainee and support group cohort; although a much larger number of women would need to studied to ascertain the validity or reliability of these findings.

\section{Qualitative Data: Attitudes, Behaviours and Perceptions}

The qualitative data has outlined the key impact that male dominated organisational cultures have upon women attempting to stay and progress in the UK construction industry. The majority of the respondents outlined the negative affect of lowered self-esteem and reduced levels of confidence due to sexist and negative attitudes, with a particular emphasis upon experiences that occur 'on site':

"Perception that a woman can't work on site or deal with build issues". 36-45 year Professional

“...Being called 'love', 'petal', 'chuck' etc... a put down”. 36-45 year Other

The role and impact of organisational cultures and pre-existing attitudes and behaviours can go much deeper than this, with women being made to feel less capable or by being undermined, with examples of prejudicial overtures:

\section{"Unwarranted attention, stereotyping". 36-45 year Professional}

"Hearing sexist comments on site". 18-24 year Administrator 
Managerially, it needs to be stated that there is some degree of support. However, this was found to be highly variable between differing individuals, company departments, work sites and organisations. The qualitative data revealed some evidence of a 'glass ceiling' (whereby women can see, but not attain higher level jobs and are blocked from career progression, Gurjao, 2006); with one respondent contentiously claiming that they had experienced regional variations in the UK:

"Hit glass ceiling in mid career (mid 30s). North West has more traditional attitudes to women than London within the construction industry".

36-45 year Professional

"I think I would have progressed further, got more opportunities if I was male". 46-55 year Professional

There is a perception from many of the respondents, that women need to perform better than their male colleagues in order to progress their careers, but that 'once proven' they seem to be finally accepted:

"I needed to prove myself more than a man but now all fine".

36-45 year Professional

"Being taken seriously as a contract manager - although I feel this is becoming less of a challenge the more knowledge I gain”.

36-45 year Professional

Linking in with the above issues, is an over-arching perception of the majority of the respondents that women are initially seen as being less capable or assumed to be in an administrative role or similar:

"Perception that women only do administrative jobs in construction". 25-35 year Administrator

"Challenge of being seen as more than a provider of tea and coffee". 25-35 year Professional

The findings outline that experiences of negative stereotypes, attitudes and behaviours seem to be prevalent. However, this forms just part of a complex picture. The following overlapping, yet distinct, key area has been identified with regards to inherent work-life balance penalties.

\section{Inflexibility in Working Practices}

Taken as a whole, the UK construction industry seems to penalise those (who in many instances are women) need to have access to more flexible and/or part-time working patterns due to family commitments.

"Part time working barrier to promotion, change in work/role". 46-55 year Professional 
"Promotion delayed until return from maternity leave (twice)".

\section{6-45 year Professional}

In many regards, there is a long-hours working culture that does not recognise the benefit of keeping hold of experienced and skilled women workers. One respondent contentiously stated that the North West is even worse in this regard, compared to the South East (London in particular):

"Long hours and changing workplaces (in construction)". 25-35 year Professional

"Private sector in the North West does not recognise part-time or flexible working. If does, best case would be 4 days a week".

\section{6-45 year Professional}

Cumulatively, the organisational cultures outlined above, both with regards to attitudes, perceptions and behaviours towards women and the inherent work-life balance penalties tend to disadvantage women (ConstructionSkills, 2008). We will now turn to the issue of support and training regarding its availability, accessibility, the type of training on offer and what has been identified by women as being in greatest need.

\section{The Central Role of Training: Identified Gaps and Needs}

Taken as a whole, the UK construction industry has a lack of opportunities (and increasingly of budget) set aside for training. This has been outlined from our focus group and semi-structured questionnaires. Indeed, a wide range of training and support has been highlighted by our participants as being required in order to facilitate the entry, retention and progression of women within the construction industry:

"Access to funding for training. Making the transition from being office based administrator to being recognised as a professional on site".

\section{5-35 year Administrator}

"I was funded for my $1^{\text {st }}$ year of HNC building through 'women in construction' but have had to get an alternative sponsor for year 2. There was no longevity in the funding".

\section{5-35 year Professional}

At present, current funding seem to be focussed upon 'kick-starting' the training with the intention of encouraging employers to further CPD processes over the longer term. However, although there are indicators that some of the larger employers are supporting this process, the findings have outlined that the majority of women have access to reduced, limited, or no CPD opportunities. Furthermore, over half of the participants who originated from the larger companies and organisations, stated that they had experienced barriers or limitations on what level or type of CPD was made available. 
From within our training cohort, there were frequent requests for training that would enhance their ability to work with confidence, to be able to deal with 'difficult' people, or teams and for assertiveness training:

"More knowledge, confidence in this industry".

36-45 year Professional

"Assertiveness, influencing skills, dealing with difficult people”.

25-35 year Professional

Of interest, and of some concern, was the finding that two of the respondents wanted to 'fit in' (or falsely appear to do so) within the male dominated organisational culture. However, it needs to be stated that this was a minority viewpoint:

"Similar interests with males".

18-24 year Administrator

"How to be fake because they've been belittled ones and want to prove a point". 25-35 year Professional

In terms of specific knowledge and skills for career progression, eleven of the respondents outlined the potential benefit of receiving training in organisational management skills and Human Resources (HR):

\section{"Possibly continuing management qualifications and look at HR qualifications".} 36-45 year Professional

It can be stated that the picture is complex with regards to training, but in many ways this complexity directly impacts upon their experiences within the organisational culture of the construction industry as a whole (Worrall et al, 2008). There are indicators from our participants that some limited training was offered merely to enable them to be 'fit for purpose' with access to additional CPD training for career progression being less readily available. Women workers often face the additional disadvantage of being considered 'less capable' or generally being 'overlooked' when particular training or career advancement opportunities arose. With this in mind, the vast majority of the respondents outlined a critical need for greater support and this is outlined and discussed in the next section.

\section{Support, Networking and Mentoring: Islands of Women}

The empirical data outlined an inherent 'isolationism' that exists for many of our trainee cohort. There were a range of recommendations that our participants recommended to counter-balance this, including:

"Mentors would be useful, plus events to target school girls - encourage them into the industry".

25-35 year Professional 
"Definitely more networking, maybe solely networking based events".

\section{8-24 year Professional}

There was a strong identified need for women to be supported with access to mentors or mentoring, both physical and virtual based. This is due to the current lack of available role models to aid in the retention and career growth of those who have already 'made it' into the sector, alongside a need to receive access to support in a very male dominated and aggressive industry sector. The women respondents called for the more proactive involvement of women within more senior management positions, to help with mentoring and job shadowing opportunities. However, this has been recognised as being quite problematic as there are few women in the more senior positions within the construction industry (Gurjao, 2006).

Many of the respondents that stated the need for mentoring and job shadowing support outlined the potential benefit of this in enabling them to learn about new career growth opportunities and in gaining additional experience that can direct their long term career goals, expectations and behaviours:

"Not all women realise what work is open to them". 36-45 year Professional

"To get relevant experience in the field in order to get on within the industry". 18-24 year Professional

Our entire 231 trainee cohort requested access to greater networking opportunities. This prompted the authors to design an interactive website which not only disseminates information regarding the latest networking and CPD opportunities, but also gives participants the option to utilise both synchronous and asynchronous Social Networking Software (SNS) facilities. There is the hope to extend the usage of this website to the rest of the UK, but at present it is mainly used by women in the North West and the Midlands due to limitations in funding.

\section{Quantitative Data: The Top Barriers}

Table 3 outlines the main barriers faced by women of differing age groups. The findings illustrate that younger women between the $25-25$ and 36-45 age group struggle the most with sexist attitudes, behaviours and perceptions.

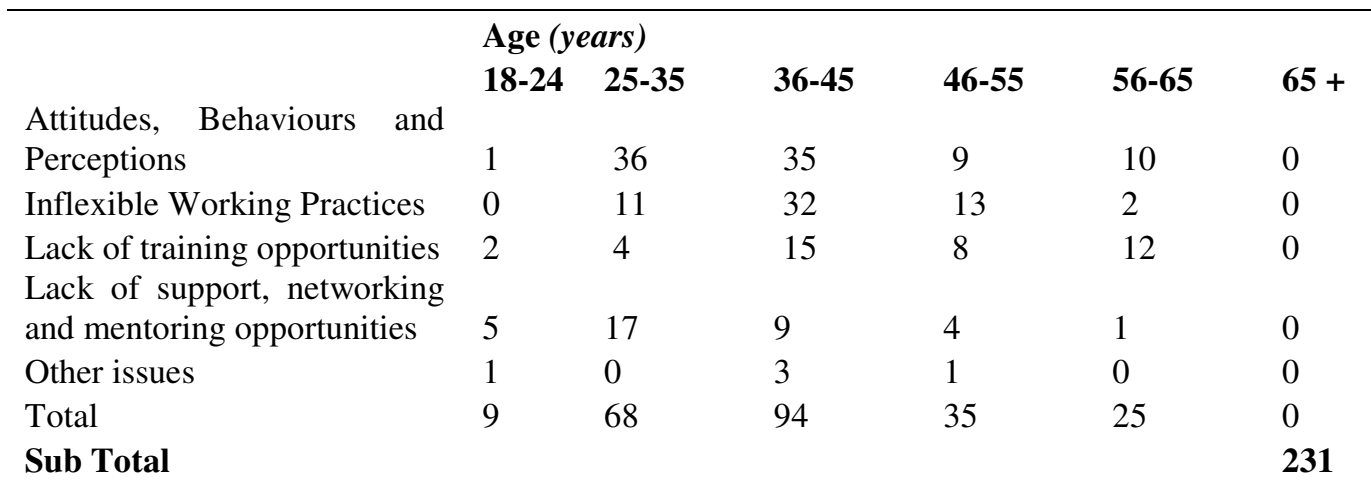

Table 2: Age groupings and individual top barrier issue 
However, almost of equal concern for women in the 36-45 year age group were inflexible working practices, which often led to problems regarding their work-life balance. We found these findings particularly interesting as they cross-fertilised with the argument of the merits of providing 'soft skills' training. It is not that women are 'deficient' in needing confidence building, communication and leadership training; it is that the unique organisational culture of the industry sector is such, that women are especially disadvantaged over men (Worrall et al, 2008). We would argue that as it is inherently difficult (and a long term vision) to be able to change the organisational culture of the industry sector itself. In the short and medium term, we argue that women would benefit from 'soft skills' training in order to be able to better traverse their way through 1) a very white male dominated industry sector in working with both colleagues and customers and 2) more confidently negotiate flexible working environments and career progression paths with senior colleagues who often have entrenched ideas regarding working cultures and the job roles of women.

We are aware that these views will no doubt draw their critics; but we would counter this by stating that it would be difficult to deny the white, male dominated organisational culture of the UK construction industry, the inflexible and long hours working culture that is especially common in the industry sector and the vast numbers of women who leave the industry which has often been described as being a 'leaky pipeline' (Gurjao, 2006).

Furthermore, the empirical findings indicate that attitudes, behaviours and perceptions are viewed as being a top barrier to women from all job roles and professions (averaging $39 \%$ of respondents). Broken down into specific job categories, $40 \%$ of professionals/managers and $39 \%$ of administrative and other workers outlined this as being the main barrier. The second most important barrier, again, for all job categories was inflexible working practices, with an average of $25 \%$ to within 1 percentile for all the job role professions. However, these averages were more greatly concentrated in the $25-35$ and 36-45 age groups. Indicators as to why this is the case include those women with growing families who experience barriers and prejudice in being allowed to accommodate areas of work-life balance in the lifecycle of their careers.

We argue that these barriers to women in the UK construction industry seem to be universally experienced, regardless of job role or profession. This strengthens the case by Gurjao (2006) on the importance of 'inclusivity' in that, in addition to attracting more women to the industry by focusing on young entrants, returnees to work following a career break, those who seek a career change and retaining those in the sector, that there is a need to understand issues surrounding how women are employed and supported in the whole industry, including the supply chain. This study has found evidence which indicates the generic problem of inflexible working practices which are experienced by women in all investigated areas of the supply chain. As these findings indicate universal problems, there could be a case for finding universal solutions. It could be argued that inflexible working environments and the inherent competitive organisational culture of the industry sector may negatively impact upon male colleagues as well due to the priority of placing 'profit over people' (Dainty et al, 2007). We would like to argue that further research is merited on the potential positive gains for the workforce as a whole, with the expansion of 'soft skills' training and supportive networks. However, what is clear is that women are also faced with white male dominated organisational cultures. It is with this additional (and one of the top 
two) identified main barriers to women that we argue for the specific merit of providing additional 'soft skills' training for women.

\section{Conclusions}

The socio-economic argument towards promoting and facilitating the entry, retention and progression of women in the UK construction industry is very strong. When viewed in purely economic terms, the industry sector is positioned as the UK's top employer and provides a sizeable proportion of its GDP. Although tempered by the current economic climate, there is still a predicted shortfall of workers, especially in middle and senior management positions, that is predicted to continue to 2011 and beyond. This is exacerbated by the existent 'time bomb' of a rapidly ageing workforce where not enough 'new blood' is coming through the ranks. The promotion and expansion of diversity to broaden the available pool of talent on offer makes good financial sense as the economy recovers from the current economic downturn. When viewed in its broader socio-economic sense, the literature review outlined a number of characteristics that are specific to the UK construction industry; including a series of historical events that have led to its current fragmentation and competitive-centric nature that places 'profit over people'. This has served to hamper an organisational climate of training and broader CPD support, for all people working in the construction industry. . It can be stated that the 'profit over people' and inflexible organisational culture of the construction industry can potentially disadvantage both men and women. However, denser theory leading from our GT leads us to argue that women also face the added problem of having to work within white male dominated organisational cultures. These findings provide a strengthened argument for the need to establish networks, mentoring and support systems for CPD for women, both in terms of promoting professional development opportunities and in providing women with the necessary 'soft skills' in communication, people management and confidence building that equip them to negotiate difficult working environments and male dominated organisational cultures. The authors would like to argue that further research is required to ascertain whether the promotion and facilitation of equality and diversity is best achieved within a 'bottom up' process, e.g. through the promotion of training through organisations such as ConstructionSkills and the enactment of CPD supportive networks, or whether a 'top down' process through legislative or managerial policies and practices, serves as a stronger instigator of positive change to organisational cultures and the barriers that women face. Only time and further analysis will tell. For its part, the authors will be further analysing the role of a 'bottom up' process and future papers will report upon the research findings and outcomes that have been achieved.

\section{References}

Agapiou A., Price A. and McCaffer R.(1995), Planning Future Construction Skill Requirements: Understanding Labour Resource Issues, Construction Management and Economics, 13, 49-161.

Bagilhole, B., Dainty, A. R. and Neale, R. H. (1997). Women in Construction: Undervalued Participants in an Undervalued Industry, Greater Access to Technology Engineering and Science, Gates, 4(1), 3-12.

BERR (2008). Department for Business, Enterprise and Regulatory Reform. Construction Statistics Annual, August, 2007. http://www.berr.gov.uk/files/file42061.pdf 
Chan, P. W., and Dainty, A. (2007). Resolving the UK construction skills crisis: a critical perspective on the research and policy agenda, Construction Management and Economics, 25(4), 375-386.

Chartered Institute of Building, (CIOB, 2008). Skills Shortages in the UK Construction Industry, CIOB, Ascot, UK.

Commission for Architecture and the Built Environment (2005) Black and Minority Ethnic Representation in the Built Environment Professions, CABE/Royal Holloway University of London, London.

ConstructionSkills (2008). Diversity within Construction. http://www.constructionskills.net/research/researchactivity/diversitywithinconstruction.asp

Dainty, A., Green, S and Bagilhole, B. (2007) People and Culture in Construction: Contexts and Challenges, in A. Dainty, S. Green, and B. Bagilhole (eds), People and Culture in Construction: Contexts and Challenges, Taylor and Francis Books Ltd., London.

Dainty, A.R.J., Ison, S.G. and Briscoe, G.H. (2005) The Construction Labour Market Skills Crisis: The perspective of Small-Medium Sized Firms. Construction Management and Economics, 23, 387-98.

Dainty, A.R.J., Bagihole, B.M. and Neale, R.H. (2000). A Grounded Theory of Women's Career Underachievement in large UK Construction Companies, Construction Management and Economics, 18, 239-250.

Egan, J. (1998). Rethinking Construction. http://www.constructingexcellence.org.U.K./pdf/rethinking\%20construction/rethinking_construc tion_report.pdf

Equalities Office (2008). Framework for a Fairer Future: The Equality Bill, http://www.parliament.the-stationery-office.co.uk/pa/cm200708/cmselect/cmberr/127/127i.pdf

Fielden, S., Davidson, M., Gale, A.W. and Davey, C.L. (2000). Women in Construction: The Untapped Resource. Construction Management and Economics, 18(1),113-121.

Gale. A. W., (1992). The Construction Industry's Male Culture must Feminize if Conflict is to be Reduced: The Role of Education as Gatekeeper to a Male Construction Industry, in Fenn, P. and Gameson, R., (1992), Construction Conflict Management and Resolution, E \& FM Spon, London.

Gale, A.W and Davidson, M.J. (2006). Managing Diversity and Equality in Construction: Initiatives and Practice. London: Taylor and Francis.

Greed, C. (2000). Women in the Construction Professions: Achieving Critical Mass, Gender, Work and Organization, 7(3), 181-96. 
Gurjao, S. (2006). Inclusivity: The Changing Role of Women in the Construction Workforce, Chartered Institute of Building Report (CIOB).

Hofstede, G. and Hofstede G.J. (2004). Cultures and Organisations: Software for the Mind, Ed. 2, London, McGraw-Hill.

Latham, M. (1994). Constructing the Team, Final Report of the joint Government/Industry Review of Procurement and Contractual Arrangements in the United Kingdom Construction Industry, HMSO.

Levene, P. (1995). The Levene Efficiency Scrutiny into Construction Procurement by Government, HMSO.

Lingard H., (2000). The Relationship between 'Family Friendly' Employment Practices and the Well-being and Satisfaction of White Collar Employees in the Construction Industry, Proceedings of the Sixteenth Annual Conference of the Association of Researchers in Construction Management, Glasgow, UK.

National Audit Office, (2001). Modernising Construction. Report by the Controller and Auditor General. HC 87 Session.

Office for National Statistics (2008). Construction Statistics Annual, Ed. No. 9, http://www.statistics.gov.uk/downloads/theme_commerce/CSA_2008_final.pdf

Schloesser, M., McCaffer, R. and Garas, F. (1999). Challenges Facing the European Construction Industry, Engineering, Construction and Architectural Management, Editorial, 6 (1), 1-2.

Worrall,L., Harris, K., Thomas, A., Stewart,R., Jessop, S., McDermott,P. Platten, A. (2008), Organisational Cultures: Retention and Progression Barriers to Women in the UK Construction Industry, International Journal of Communities, Organisations and Nations, 8(3), 31-40. 